\title{
Heparanase Level and Procoagulant Activity Are Increased in Thalassemia and Attenuated by Janus Kinase 2 Inhibition
}

\author{
Hussam Ghoti, ${ }^{*}$ Shanny Ackerman, ${ }^{\dagger}$ Stefano Rivella, ${ }^{\ddagger}$ Carla Casu, ${ }^{\ddagger}$ and Yona Nadir
}

\begin{abstract}
From the European Center for Cancer and Cell Therapy (ECCT), Nicosia, Cyprus; the Thrombosis and Hemostasis Unit, ${ }^{\dagger}$ Rambam Health Care Campus, Ruth and Bruce Rappaport Faculty of Medicine, Technion, Haifa, Israel; and the Department of Pediatrics, ${ }^{\ddagger}$ Division of Hematology, Children’s Hospital of Philadelphia (CHOP), Philadelphia, Pennsylvania
\end{abstract}

\author{
Accepted for publication \\ July 7, 2020. \\ Address correspondence to \\ Yona Nadir, M.D., Ph.D., \\ Thrombosis and Hemostasis \\ Unit, Rambam Health Care \\ Campus, HaAliya HaShniya \\ Street 8, PO Box 9602, Haifa \\ 31096, Israel. E-mail: y \\ nadir@rambam.health.gov.il.
}

\begin{abstract}
Patients with thalassemia exhibit an increased risk of thrombotic events that is augmented after splenectomy. Heparanase protein enhances cancer progression, angiogenesis, and inflammation; it also activates the coagulation system through direct interaction with tissue factor (TF). Additionally, erythropoietin, which is elevated in anemic patients, up-regulates heparanase expression via the Janus kinase 2 (JAK-2) pathway. This study aimed was to explore the heparanase profile in thalassemia. Coagulation factors were analyzed via immunostaining, enzyme-linked immunosorbent assay, and heparanase procoagulant activity assay. In spleen specimens of thalassemia major patients, a higher level of heparanase staining was observed compared with control spleens resected after trauma $(P<0.001)$. Higher heparanase levels, heparanase and TF procoagulant activity, and erythropoietin levels were found in the plasma of 67 thalassemia major patients compared with 29 control subjects. No difference was found in pediatric patients (23 of 67) compared with adults or splenectomized versus nonsplenectomized patients. Higher levels of heparanase, TF, TF pathway inhibitor, and TF pathway inhibitor-2 were observed in liver, spleen, heart, and kidney tissues of thalassemia intermedia mice $\left(\mathrm{Hbb}^{\text {th } 3 /+}\right)$. These protein levels significantly reduced when mice were treated with the JAK-2 inhibitor ruxolitinib $(P<0.0001)$. In summary, heparanase levels are elevated in thalassemia, which may contribute to thrombotic phenomena in these patients. Inhibition of heparanase or the JAK-2 pathway may reduce thrombotic risk in thalassemia. (Am J Pathol 2020, 190: 2146-2154; https://doi.org/10.1016/j.ajpath.2020.07.011)
\end{abstract}

Patients with thalassemia have an increased risk of thrombosis that is elevated after splenectomy. ${ }^{1}$ Heparanase is a protein that has been shown to enhance inflammation, tumor growth, and angiogenesis. ${ }^{2}$ Previous studies have shown that heparanase also activates the coagulation system by enhancing tissue factor (TF) activity. ${ }^{3}$ In addition, it upregulates the expression of $\mathrm{TF}^{4}$ and releases $\mathrm{TF}$ pathway inhibitor (TFPI) from the endothelial cell surface, resulting in a prothrombotic state in endothelial cells. ${ }^{5}$ It is also shown that activation of the JAK-2 pathway induces upregulation of heparanase. The latter effect is exerted by erythropoietin, which is known to activate JAK-2, and is abolished by ruxolitinib, an inhibitor of this pathway. ${ }^{6}$ High levels of erythropoietin in patients with $\beta$-thalassemia have been shown to be associated with increased activation of the
JAK-2 pathway. ${ }^{7}$ Given that high erythropoietin levels up-regulate heparanase expression, we hypothesized that heparanase levels and procoagulant activity could be enhanced in patients with thalassemia major.

\footnotetext{
Supported by the National Institute of Diabetes and Digestive and Kidney Diseases, NIH grants R01 DK090554 (S.R.) and R01 DK095112 (S.R).

Disclosures: S.R. has served as a consultant for BVF Partners L.P., Cambridge Healthcare Research, Celgene Corp, First Manhattan Co., FORMA Therapeutics, Ghost Tree Capital, Incyte Corp, Keros Therapeutics, Inc., Noble Insight, Protagonist Therapeutics, Rallybio, LLC, Sanofi Aventis U.S., Inc., Slingshot Insight, Techspert.io, venBio Select LLC, the Scientific Advisory Board of Disc Medicine, IONIS Pharmaceuticals, and Meira GTx, and has stock options in Meira GTx.

In memory of Prof. Eliezer Rachmilewitz, who initiated the project but unfortunately passed away in December 2017.
} 


\section{Materials and Methods}

\section{Study Group}

The study was approved by the Institutional Ethics Committee on Human Research at the Rambam Health Care Campus (Haifa, Israel). The inclusion criterion was confirmed diagnosis of thalassemia major. Exclusion criteria were acute infection or hormonal treatment. Sixty-seven patients with thalassemia major were recruited. Twentythree of the 67 patients were aged $<18$ years. The control group included 29 healthy adult individuals not using any drugs or hormonal therapy.

\section{Animal Model}

The animal study was conducted under the protocols approved by the Institutional Animal Care and Use Committee of the Children's Hospital of Philadelphia. The mouse model for $\beta$-thalassemia intermedia $H b b^{\text {th } 3 /+}$ was purchased from The Jackson Laboratory (Bar Harbor, ME). ${ }^{8}$ All animals (2.5- to 3.5-month-old male mice in C57BL/6 background) were bred at the mouse facility of the Children's Hospital of Philadelphia. Based on previous experiments, ${ }^{9}$ no sex difference in response to JAK-2 inhibitor treatment was expected. Only male mice were used in the current study to avoid hormonal effects on heparanase levels.

\section{Drug Preparation and Administration}

INCB018424 (ruxolitinib) was purchased from ChemieTek (Indianapolis, IN) and administered for 10 days, twice daily by oral gavage, at a dose of $180 \mathrm{mg} / \mathrm{kg}$. The stock solution was in dimethyl sulfoxide. After the 10-day period, wildtype animals (C57BL/6), as well as those with thalassemia $\left(H b b^{\text {th } 3 /+}\right)$ or thalassemia treated with a JAK-2 inhibitor (ruxolitinib), were euthanized and their organs embedded in formalin.

\section{Reagents and Antibodies}

A single-chain GS3 heparanase gene construct, comprising the $8 \mathrm{kDa}$ and $50 \mathrm{kDa}$ heparanase subunits $(8+50)$, was purified from the conditioned medium of baculovirusinfected cells. GS3 heparanase was assayed for the presence of bacterial endotoxin (Biological Industries, Beit Haemek, Israel) using the gel-clot technique (limulus amebocyte lysate test) and was found to contain $<10 \mathrm{pg} / \mathrm{mL}$ of endotoxin. ${ }^{4}$ Polyclonal antibody 1453 against the entire $65 \mathrm{kDa}$ heparanase precursor, isolated from the conditioned medium of heparanase-transfected HEK-293 cells, was raised in rabbits. The antibody was affinity purified on immobilized, bacterially expressed $50 \mathrm{kDa}$ heparanase glutathione $S$-transferase fusion protein. ${ }^{10}$ Monoclonal antiheparanase antibody 1E1 was generated by immunizing $\mathrm{BALB} / \mathrm{C}$ mice with the entire $65 \mathrm{kDa}$ heparanase protein.
Antibody 733 against a 15 -amino-acid peptide, mapping at the $\mathrm{N}$ terminus of the $50 \mathrm{kDa}$ heparanase subunit, was raised in rabbits. ${ }^{10}$ Recombinant human factor VIIa and plasmaderived human factor $\mathrm{X}$ were purchased from Sekisui Diagnostics, Inc. (Stamford, CT). All coagulation factors were dissolved in double-distilled water. The chromogenic substrate to factor Xa (I.D. 222, solubility: Tris buffer, $\mathrm{pH}$ 8.4) was purchased from Sekisui Diagnostics (Stamford, CT). Bovine factor Xa was obtained from Sigma-Aldrich Corp (St. Louis, MO). Polyclonal anti-human TF and polyclonal anti-human TFPI antibodies were purchased from Santa Cruz Biotechnology (Dallas, TX). Polyclonal anti-TFPI-2 was purchased from Bioss Antibodies (Woburn, MA). Human erythropoietin enzyme-linked immunosorbent assay (ELISA) kit RAB0654 was purchased from Sigma (St. Louis, MO).

\section{Histology Stains}

Staining of formalin-fixed, paraffin-embedded 5- $\mu$ sections was performed. Slides were deparaffinized with xylene, rehydrated, and endogenous peroxidase activity was quenched for 30 minutes by $3 \%$ hydrogen peroxide in methanol. Slides were then subjected to antigen retrieval by boiling (20 minutes) in $10 \mathrm{mmol} / \mathrm{L}$ citrate buffer, $\mathrm{pH}$ 6. Slides were incubated with $10 \%$ normal goat serum in phosphate-buffered saline (PBS) for 60 minutes to block nonspecific binding followed by incubation ( 20 hours, $4^{\circ} \mathrm{C}$ ) with anti-TF, anti-TFPI, anti-TFPI-2, or anti-heparanase 733 antibodies, diluted 1:100 in blocking solution. Slides were then extensively washed with PBS containing $0.01 \%$ Triton X-100 and incubated with a secondary reagent (EnVision kit; Dako, Glostrup, Denmark) or secondary fluorescent reagent (Jackson ImmunoResearch Laboratories, West Grove, PA) according to the manufacturer's instructions. After additional washes, color was developed with the AEC reagent (Sigma). Analyses of tissue immunohistochemistry results were performed by two of the authors unaware of the slide allocation. Discrepancies in the analyses were reconciled after assessment by a third reviewer. Five high-power fields were evaluated in each stained slide. Staining intensity was scored as follows: 0 , no staining; 1 , weak intensity; 2 , moderate intensity; and 3, marked intensity. Representative intensity of staining is shown.

\section{Plasma Preparation}

Fresh venous blood samples of patients and control subjects were collected into tubes with $3.2 \%$ sodium citrate. Blood samples were centrifuged at $1500 \times g$ for 15 minutes. Plasma aliquots were frozen at $-70 \pm 5^{\circ} \mathrm{C}$. Plasma aliquots for assays were thawed only once.

\section{Heparanase ELISA}

Wells of microtiter plates were coated $\left(18\right.$ hours, $\left.48^{\circ} \mathrm{C}\right)$ with $2 \mu \mathrm{g} / \mathrm{mL}$ of anti-heparanase monoclonal antibody $1 \mathrm{E} 1$ in 
$50 \mu \mathrm{L}$ of coating buffer $\left(0.05 \mathrm{~mol} / \mathrm{L} \mathrm{Na} \mathrm{CO}_{3}, 0.05 \mathrm{~mol} / \mathrm{L}\right.$ $\mathrm{NaHCO}_{3}, \mathrm{pH} 9.6$ ) and then blocked with $2 \%$ bovine serum albumin in PBS for 1 hour at $37^{\circ} \mathrm{C}$. Samples $(200 \mu \mathrm{L})$ were loaded in triplicates and incubated for 2 hours at room temperature, followed by the addition of $100 \mu \mathrm{L}$ of antibody $1453(1 \mu \mathrm{L} / \mathrm{mL})$ for 2 hours at room temperature. Horseradish peroxidase-conjugated goat anti-rabbit $\mathrm{IgG}$ $(1: 20,000)$ in a blocking buffer was added (1 hour, room temperature), and the reaction was visualized by the addition of $50 \mu \mathrm{L}$ of a chromogenic substrate (TMB; MP Biomedicals, Eschwege, Germany) for 30 minutes. The reaction was stopped with $100 \mu \mathrm{L}$ of $\mathrm{H}_{2} \mathrm{SO}_{4}$, and absorbance at 450 $\mathrm{nm}$ was measured by using a heparanase ELISA plate reader (PowerWave XS; BioTek Instruments, Winooski, VT). Plates were washed five times with a washing buffer [PBS, pH 7.4 containing $0.1 \%(w / v)$ Tween 20] after each step. As a reference for quantification, a standard curve was established by serial dilutions of recombinant $8+50$ GS3 heparanase $(390 \mathrm{pg} / \mathrm{mL}-25 \mathrm{ng} / \mathrm{mL}){ }^{11}$

\section{Heparanase Procoagulant Activity Assay}

As previously reported, ${ }^{12}$ a basic experiment of factor Xa generation was performed in the following manner. The aforementioned concentrations were final. Twenty-five microliters of plasma, recombinant human factor VIIa (0.04 $\mu \mathrm{mol} / \mathrm{L})$, and plasma-derived human factor $\mathrm{X}(1.4 \mu \mathrm{mol} / \mathrm{L})$ were incubated in $50 \mu \mathrm{L}$ of the assay buffer $[0.06 \mathrm{~mol} / \mathrm{L}$ Tris, $0.04 \mathrm{~mol} / \mathrm{L} \mathrm{NaCl}, 2 \mathrm{mmol} / \mathrm{L} \mathrm{CaCl}_{2}, 0.04 \%$ (w/v) bovine serum albumin, $\mathrm{pH} 8.4$ ] at a total volume of $125 \mu \mathrm{L}$ in a 96-well sterile plate. After 15 minutes at $37^{\circ} \mathrm{C}$, a chromogenic substrate to factor Xa was added $(1 \mathrm{mmol} / \mathrm{L})$. After 20 minutes, the reaction was stopped with $50 \mu \mathrm{L}$ of glacial acetic acid, and the level of factor Xa generation was determined by using an ELISA plate reader (PowerWave XS). Because heparins had been shown to abrogate the TF/ heparanase complex, ${ }^{3}$ in parallel, essentially the same assay was performed but with the addition of fondaparinux (2.5 $\mu \mathrm{g} / \mathrm{mL}$ ) to the assay buffer. Bovine factor Xa diluted in the assay buffer was used to generate a standard curve. The subtraction of the first assay result from the second assay result determined heparanase procoagulant activity. Thus, the assay provided three results: heparanase procoagulant activity, TF activity, and TF + heparanase procoagulant activity.

\section{Statistical Analysis}

Data were evaluated by using SPSS software for Windows version 13.0 (IBM SPSS Statistics, IBM Corporation, Armonk, NY). For variables with normal distribution, the parametric $t$-test was used, and variables were summarized as means $\pm \mathrm{SD}$. For variables with nonnormal distribution, the nonparametric $U$-test was used. The significance level was set at $P<0.05$. The Pearson correlation test was used to evaluate correlations as indicated in the text.

\section{Results}

\section{Heparanase Levels in Spleen Tissue Resected due to} Thalassemia or Trauma

To provide clinical relevance to the assumption that anemiarelated increased erythropoietin levels in patients with thalassemia could up-regulate the expression of heparanase, spleen tissues were compared from patients splenectomized due to trauma or $\beta$-thalassemia major (Figure 1). Increased heparanase staining intensity was observed in the blood vessels of spleen samples derived from patients with thalassemia $(n=5)$ compared with those obtained from trauma patients $(n=5$, $P<0.001)$. It was previously reported that disseminated intravascular coagulation reduced heparanase levels. ${ }^{13}$ The current study evaluated cases that, according to presurgery coagulation blood tests that assessed prothrombin time, activated partial thromboplastin time, and fibrinogen levels, were not in disseminated intravascular coagulation.

\section{Heparanase, TF, and Erythropoietin in Patients with $\beta$-Thalassemia Major}

The results (Figure 1) encouraged us to study the plasma samples of 67 patients with thalassemia major (44 adults and 23 patients aged $<18$ years). Characteristics of the study group are shown (Table 1.). Significant differences between the adult and pediatric patients were observed in ferritin levels and the number of splenectomized patients. In plasma tests, heparanase levels (Figure 2A) and procoagulant activity (Figure 2B) were significantly higher in the adult patients with thalassemia $(n=44)$ compared with control subjects $(n=29$, $P<0.0001)$. In contrast, no significant difference in these parameters was noted between adult and pediatric thalassemia patients $(n=23)$, with both groups exhibiting higher values than control subjects. Of note, the pediatric and control groups were not directly compared because they were not age matched. In addition, no significant difference in the evaluated parameters was found between patients postsplenectomy compared with nonsplenectomized patients. Results of TF activity and erythropoietin level assessment were similar in pattern to those of the heparanase data (Figure 2, A-D). Likewise, comparison of the aforementioned parameters from eight nonsplenectomized adult patients versus those of 36 splenectomized adults identified no significant differences. Using Pearson correlation analysis, a medium-strength positive correlation was shown between heparanase levels/heparanase procoagulant activity, heparanase levels/erythropoietin levels, and heparanase procoagulant activity/erythropoietin levels (Figure 2E).

Heparanase Levels Are Elevated in Thalassemia Mouse Tissues and Can Be Attenuated by a JAK-2 Inhibitor

Findings of heparanase staining of heart, kidney, spleen, and liver tissues obtained from control mice, animals with 

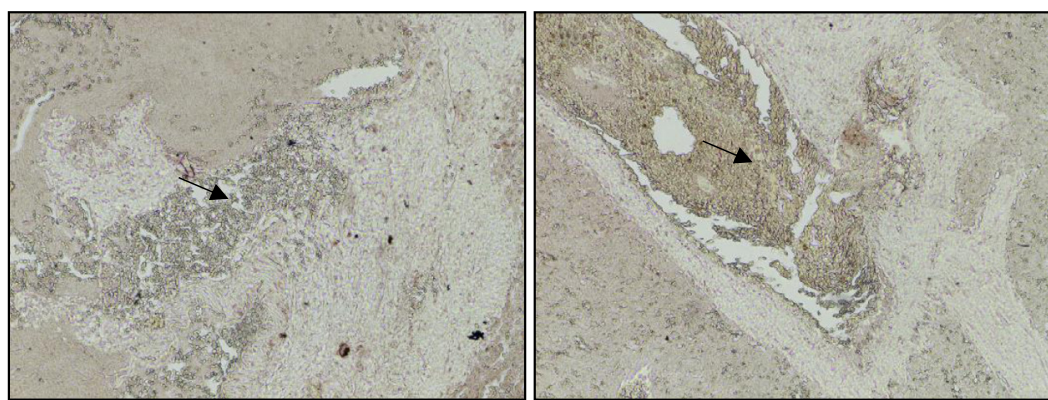

Heparanase staining intensity in spleen, mean of 5 fields of each organ

\begin{tabular}{|l|l|l|l|l|l|}
\hline & Absence & Weak & Moderate & Strong & $P$ value \\
\hline Trauma (left) & & 2 & 3 & & \\
\hline Thalassemia (right) & & & 2 & 3 & $<0.001$ \\
\hline
\end{tabular}

Figure 1 Heparanase levels in spleen tissues resected due to thalassemia or trauma. Increased heparanase staining intensity is observed in the intraluminal blood vessel space (black arrows) of the spleen sample derived from patients with thalassemia (right panel) compared with those from trauma patients (left panel). Representative images, captured with a Nikon E995 digital camera (Nikon, Tokyo, Japan). Contingency table (bottom panel) showing staining intensity in the spleen. In each group, five spleen tissue samples were evaluated, and the mean staining intensity of five different fields in each slide was calculated. Significance was determined by using the $U$-test. $n=5$ patients with thalassemia and trauma patients. Original magnification, $\times 50$. $\beta$-thalassemia intermedia, and those with thalassemia treated with a JAK-2 inhibitor were compared (Figure 3). Staining intensity in the blood vessels was significantly higher in all the tissues derived from thalassemia mice compared with control mice tissue and was dramatically reduced in the tissues of animals treated with the JAK-2 inhibitor ruxolitinib for 10 days, before euthanasia.

\section{TF, TFPI, and TFPI-2 Levels Are Elevated in the Tissues of Thalassemia Mice and Are Decreased with Exposure to a JAK-2 Inhibitor}

Results of TF, TFPI, and TFPI-2 staining of liver (Figure 4A), kidney (Figure 4B), and heart (Figure 4C) tissues, derived from control animals, untreated thalassemia mice, and those treated with a JAK-2 inhibitor, were compared. Similar to the heparanase pattern, in terms of the evaluated parameters, staining intensity in the blood vessels was significantly higher in thalassemia mouse tissues compared with tissues in control mice and was dramatically reduced in tissues of mice exposed to ruxolitinib.

\section{Discussion}

The current study identified elevated levels of heparanase in blood vessels of spleen samples derived from patients with $\beta$-thalassemia major compared with samples originating from trauma patients. These findings were further strengthened by the analysis of plasma samples from 67 patients with thalassemia major relative to 29 control subjects. Not only were the heparanase levels and procoagulant activity higher in the study group, but the TF activity was also significantly elevated. No difference was found in results either between adult and pediatric patients or between splenectomized individuals relative to nonsplenectomized individuals. Indeed, most splenectomized patients were adults, and most nonsplenectomized individuals were pediatric patients. When comparing the adult splenectomized group ( $n=36$ ) versus the adult nonsplenectomized group $(n=8)$, again no significant difference was found in the results. Interestingly, the dynamics of erythropoietin levels displayed a pattern similar to that of heparanase and $\mathrm{TF}$, which could be suggestive of a potential contributing factor

Table 1 Demographic Characteristics of the Study Group

\begin{tabular}{|c|c|c|c|c|}
\hline Characteristics & $\begin{array}{l}\text { Control } \\
\text { subjects }\end{array}$ & Adult patients & Pediatric patients & $P$ value \\
\hline Age, years & $23 \pm 3$ & $22 \pm 6$ & $8 \pm 3$ & $\begin{array}{l}0.91 \text {, control subjects versus adults } \\
P<0.0001 \text {, adults versus pediatric }\end{array}$ \\
\hline Female sex, $n(\%)$ & $15(52)$ & $21(48)$ & $13(57)$ & 0.85 \\
\hline Hemoglobin level, $\mathrm{g} / \mathrm{dL}$ & $14.8 \pm 0.6$ & $7.4 \pm 0.9$ & $8.1 \pm 0.5$ & $\begin{array}{l}P<0.001 \text {, control subjects versus adults } \\
0.82 \text {, adults versus pediatric }\end{array}$ \\
\hline Time between blood transfusions, weeks & NA & $3.7 \pm 0.6$ & $3.5 \pm 1.1$ & 0.81 \\
\hline Splenectomized patients, $n(\%)$ & NA & $36(81)$ & $2(9)$ & $P<0.0001$ \\
\hline
\end{tabular}

Data are expressed as means $\pm S D$, unless otherwise indicated.

$n=29$ control subjects; $n=44$ adult patients; $n=23$ pediatric patients.

NA, not applicable. 

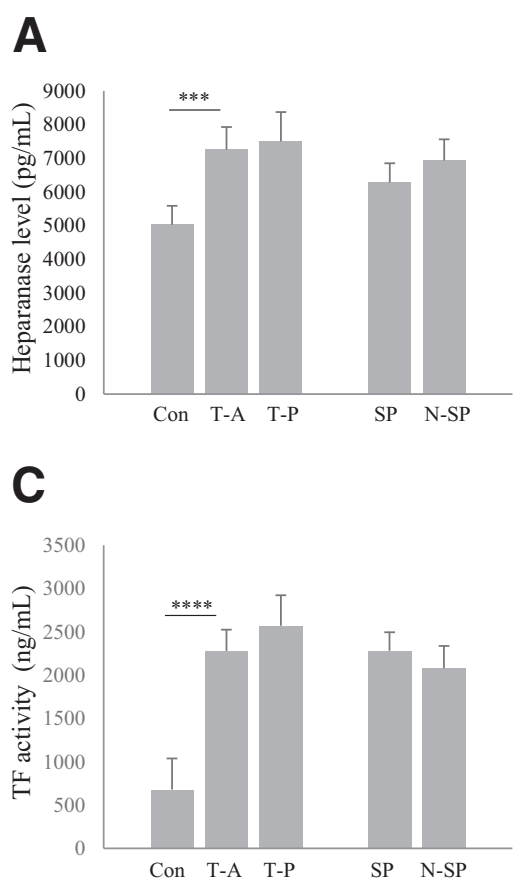

E

\begin{tabular}{|l|l|l|}
\hline & Pearson correlation $(r)$ & $P$ value \\
\hline $\begin{array}{l}\text { Heparanase level/ } \\
\text { heparanase procoagulant activity }\end{array}$ & 0.453 & 0.007 \\
\hline Heparanase level/TF activity & 0.223 & 0.06 \\
\hline $\begin{array}{l}\text { Heparanase procoagulant activity/ } \\
\text { TF activity }\end{array}$ & 0.155 & 0.09 \\
\hline $\begin{array}{l}\text { Heparanase level/ } \\
\text { erythropoietin level }\end{array}$ & 0.326 & 0.02 \\
\hline $\begin{array}{l}\text { Heparanase procoagulant activity/ } \\
\text { erythropoietin level }\end{array}$ & 0.405 & 0.001 \\
\hline TF activity/erythropoietin level & 0.092 & 0.2 \\
\hline
\end{tabular}

\section{D}

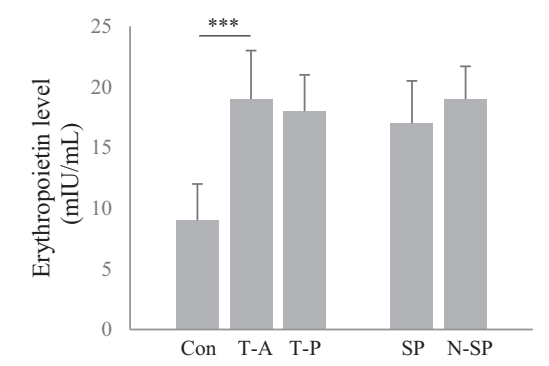

B

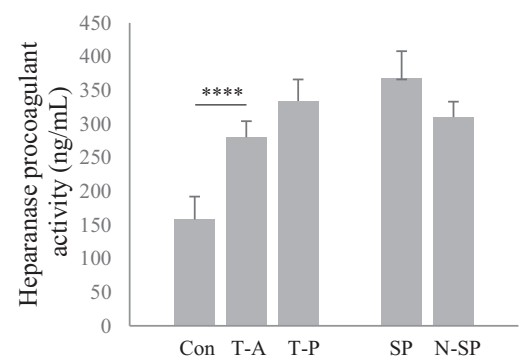

Figure 2 Heparanase, tissue factor (TF), and erythropoietin in patients with $\beta$-thalassemia major. $\mathbf{A}$ and $\mathbf{B}$ : Heparanase levels $(\mathbf{A})$ and procoagulant activity (B) are significantly higher in adult patients with thalassemia (T-A) compared with control subjects (Con). No significant difference in these parameters is observed between adult and pediatric patients with thalassemia (T-P). In addition, results are similar in splenectomized (SP) compared with nonsplenectomized (N-SP) patients. C and D: TF activity and erythropoietin levels are similar in pattern to those of heparanase. E: A medium-strength positive correlation is shown between heparanase levels/heparanase procoagulant activity, heparanase levels/erythropoietin levels, and heparanase procoagulant activity/ erythropoietin levels. Data are expressed as means $\pm \mathrm{SD}$. The $t$-test was used in $\mathbf{A}-\mathbf{D}$; the Pearson correlation test was used in E. $n=44$ adult patients with thalassemia (A-D); $n=29$ control subjects (A-D); $n=23$ pediatric patients with thalassemia $(\mathbf{A}-\mathbf{D}) . \quad{ }^{* * * P}<0.001$, $* * * * P<0.0001$. to each other. The fact that heparanase levels and procoagulant activity positively correlated with erythropoietin levels, while no correlation was found between TF activity and erythropoietin, could imply that TF activity might be determined by other factors. Using the thalassemia mouse model, it was shown that in the blood vessels of all evaluated tissues, heparanase levels, as well as TF, TFPI, and TFPI-2, were elevated compared with levels in control mice. However, these protein levels were dramatically reduced with inhibition of the JAK-2 pathway.

High levels of erythropoietin were previously reported in patients with thalassemia. ${ }^{14,15}$ The current study not only showed higher levels of this hormone in patients compared with control subjects but also revealed no significant difference in its levels between splenectomized and nonsplenectomized patients. Furthermore, in earlier studies of $\beta$-thalassemia with its related anemia and hypoxia, high levels of erythropoietin were found to be associated with increased activation of the JAK-2 pathway. ${ }^{7}$ It was previously reported that in several tumor cell lines, JAK-2 activation up-regulated the expression of heparanase protein, and activation of JAK-2 by erythropoietin induced an increase in heparanase levels. ${ }^{6}$ In the current study, patients with thalassemia major displayed increased erythropoietin and heparanase levels in plasma. It is possible that in thalassemia, elevated erythropoietin production up-regulates heparanase expression via JAK-2.

Remarkably, in the thalassemia mouse model, elevated heparanase levels were accompanied with increased levels of key coagulation players such as TF, TFPI, and TFPI-2; this scenario is in line with previous findings. ${ }^{16-18}$ The tetrad of heparanase, TF, TFPI, and TFPI- 2 may be partially explained by the fact that heparanase up-regulates the expression of $\mathrm{TF}^{4}$ and TFPI. ${ }^{5}$ Moreover, the heparanase effect on TFPI is not limited to up-regulation of its expression; heparanase is also found to induce TFPI release 
A

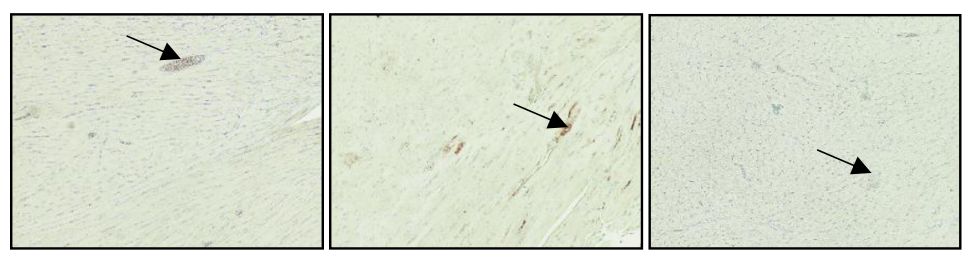

B

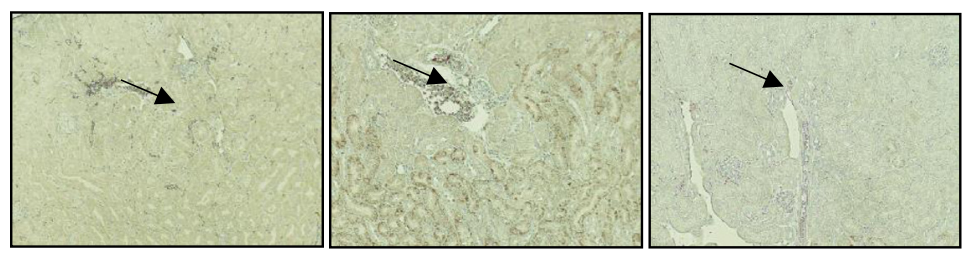

C
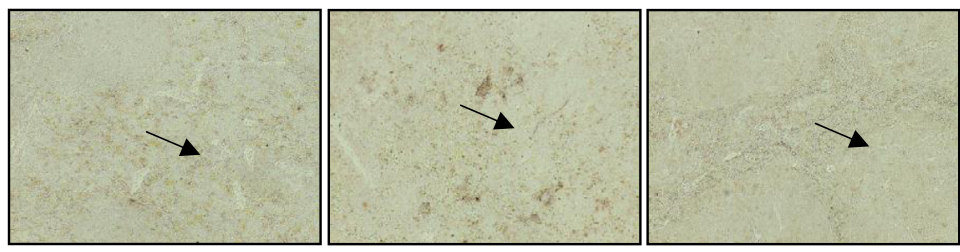

D

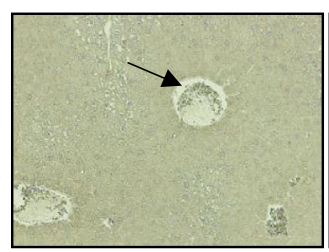

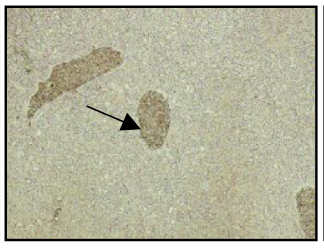

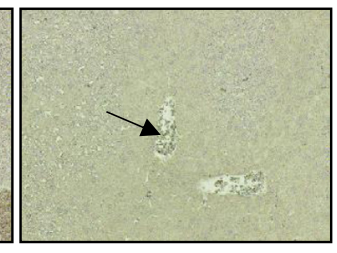

Heparanase staining intensity in heart,

mean of 5 fields of each organ

\begin{tabular}{|l|l|l|l|l|l|}
\hline & Absence & Weak & Moderate & Strong & $P$ value \\
\hline Control (left) & 1 & 4 & & & \\
\hline Thalassemia (middle) & & & 2 & 3 & $<0.0001$ \\
\hline $\begin{array}{l}\text { Thalassemia }+ \text { JAK-2 inhibitor (right) } \\
\text { J }\end{array}$ & 4 & 1 & & & $<0.0001$ \\
\hline
\end{tabular}

Heparanase staining intensity in kidney,

mean of 5 fields of each organ

\begin{tabular}{|l|l|l|l|l|l|}
\hline & Absence & Weak & Moderate & Strong & $P$ value \\
\hline Control (left) & & 5 & & & \\
\hline Thalassemia (middle) & & & 3 & 2 & $<0.0001$ \\
\hline $\begin{array}{l}\text { Thalassemia }+ \\
\text { JAK-2 inhibitor (right) }\end{array}$ & 4 & 1 & & & $<0.0001$ \\
\hline
\end{tabular}

Heparanase staining intensity in spleen,

mean of 5 fields of each organ

\begin{tabular}{|l|l|l|l|l|l|}
\hline & Absence & Weak & Moderate & Strong & $P$ value \\
\hline Control (left) & & 5 & & & \\
\hline Thalassemia (middle) & & & 4 & 1 & $<0.001$ \\
\hline $\begin{array}{l}\text { Thalassemia + JAK-2 } \\
\text { inhibitor (right) }\end{array}$ & 2 & 3 & & & $<0.0001$ \\
\hline
\end{tabular}

Heparanase staining intensity in liver,

mean of 5 fields of each organ

\begin{tabular}{|l|l|l|l|l|l|}
\hline & Absence & Weak & Moderate & Strong & $P$ value \\
\hline Control (left) & & 5 & & & \\
\hline Thalassemia (middle) & & & 1 & 4 & $<0.0001$ \\
\hline $\begin{array}{l}\text { Thalassemia + } \\
\text { JAK-2 inhibitor (right) }\end{array}$ & 1 & 4 & & & $<0.0001$ \\
\hline
\end{tabular}

Figure 3 Heparanase levels are elevated in thalassemia mouse tissues, which can be attenuated by a Janus kinase 2 (JAK-2) inhibitor. Heparanase staining of heart (A), kidney (B), spleen (C), and liver (D) tissues derived from control mice, animals with untreated thalassemia, and those treated with the JAK-2 inhibitor were compared. Staining intensity in the blood vessels (black arrows) is significantly higher in the thalassemia mouse tissues compared with control tissue and is dramatically reduced in tissues of mice treated for 10 days with the JAK-2 inhibitor ruxolitinib, before euthanasia. Representative images, captured with a Nikon E995 digital camera (Nikon, Tokyo, Japan). Contingency table (right panels) showing staining intensity in tissues. In each group, five mouse tissue samples were evaluated, and the mean staining intensity of five different fields in each slide was calculated. Significance was determined by using the $U$-test. $n=5$ (A-D). Original magnification, $\times 50(\mathbf{A}-\mathbf{D})$.

from endothelial cells, rendering the endothelial cell surface more procoagulant. ${ }^{5}$ The effect of heparanase on the expression of TF, TFPI, and TFPI- 2 was shown in a recently published work reporting data on a heparanase overexpression mouse model. ${ }^{16}$ It was found that in the microcirculation of the investigated tissues (lung and liver), heparanase levels as well as TF, TFPI, and TFPI-2 levels were increased. The latter proteins were also assessed in another study, using a mouse model of malignant pleural effusion to evaluate a peptide derived from TFPI- 2 that 
A

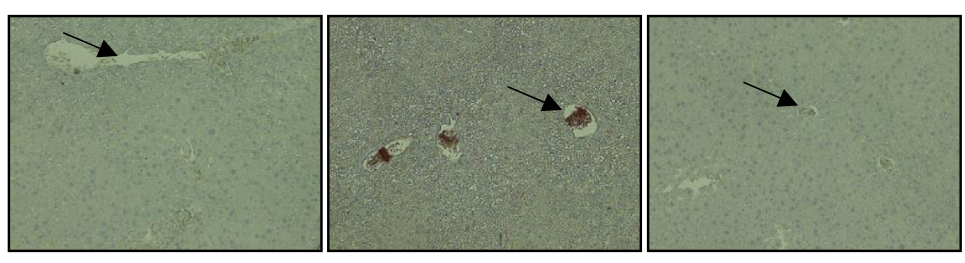

B
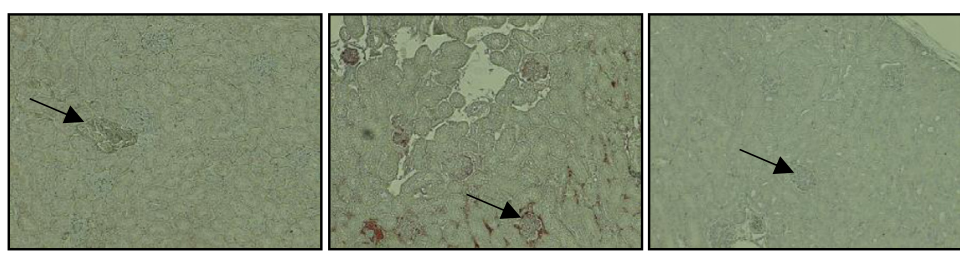

C

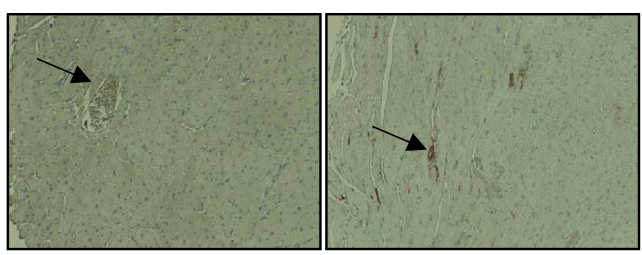

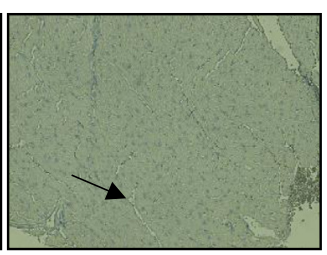

TF staining intensity in liver, mean of 5 fields of each organ

\begin{tabular}{|l|l|l|l|l|l|}
\hline & Absence & Weak & Moderate & Strong & $P$ value \\
\hline Control (left) & 1 & 4 & & & \\
\hline Thalassemia (middle) & & & 1 & 4 & $<0.0001$ \\
\hline $\begin{array}{l}\text { Thalassemia + JAK-2 } \\
\text { inhibitor (right) }\end{array}$ & 2 & 3 & & & $<0.0001$ \\
\hline
\end{tabular}

TFPI staining intensity in kidney,

mean of 5 fields of each organ

\begin{tabular}{|l|l|l|l|l|l|}
\hline & Absence & Weak & Moderate & Strong & $P$ value \\
\hline Control (left) & & 5 & & & \\
\hline Thalassemia (middle) & & & 1 & 4 & $<0.0001$ \\
\hline $\begin{array}{l}\text { Thalassemia + } \\
\text { JAK-2 inhibitor (right) }\end{array}$ & 1 & 4 & & & $<0.0001$ \\
\hline
\end{tabular}

TFPI-2 staining intensity in heart,

mean of 5 fields of each organ

\begin{tabular}{|l|l|l|l|l|l|}
\hline & Absence & Weak & Moderate & Strong & $P$ value \\
\hline Control (left) & 1 & 4 & & & \\
\hline Thalassemia (middle) & & & 1 & 4 & $<0.0001$ \\
\hline $\begin{array}{l}\text { Thalassemia }+ \\
\text { JAK-2 inhibitor (right) }\end{array}$ & 1 & 4 & & & $<0.0001$ \\
\hline
\end{tabular}

Figure 4 Tissue factor (TF), TF pathway inhibitor (TFPI), and TFPI-2 are elevated in tissues of thalassemia mice, which can be attenuated by using a Janus kinase 2 (JAK-2) inhibitor. TF, TFPI, and TFPI-2 staining of liver (A), kidney (B), and heart (C) tissues derived from control mice, animals with untreated thalassemia, and those treated with a JAK-2 inhibitor were compared. In accordance with previous findings and similar to heparanase levels, ${ }^{6}$ staining intensity in the blood vessels (black arrows) in terms of these parameters is significantly higher in the thalassemia mouse tissues compared with control mice tissue and is dramatically reduced in tissues of mice treated for 10 days with the JAK-2 inhibitor ruxolitinib. Representative images, captured with a Nikon E995 digital camera (Nikon, Tokyo, Japan). Contingency table (right panels) showing staining intensity in tissues. Significance was determined by using the U-test. $n=5(\mathbf{A}-\mathbf{C})$. Original magnification, $\times 50(\mathbf{A}-\mathbf{C})$.

inhibits heparanase interaction with TF. This heparanase inhibitor not only reduced the heparanase level but also attenuated the levels of TF, TFPI, and TFPI- 2 in the pleura and microcirculation adjacent to the pleural cavity. ${ }^{19}$ Interestingly, in the tissues derived from mice treated with the JAK-2 inhibitor, the degree of coagulation protein staining was even lower compared with control findings. This result may imply that JAK-2 pathway activation affects the constitutional levels of these proteins in the perivascular/ intravascular space.

Patients with thalassemia seem to exhibit an increased risk of thrombosis. The mechanisms contributing to coagulation system activation are various and include chronic platelet activation, alteration of red blood cell membranes, abnormal expression of adhesion molecules on vascular endothelial cells, and dysregulation of hemostasis. ${ }^{1}$ Coagulation system activation markers, including low levels of proteins $\mathrm{C}$ and $\mathrm{S}$, and increased thrombinantithrombin levels, were observed in these patients. ${ }^{20}$
Regular transfusions were found to decrease the risk of thrombosis, whereas splenectomy significantly increased such risk. ${ }^{1}$ Along with thrombocytosis that frequently occurs after splenectomy, Trinchero et $\mathrm{al}^{21}$ reported a prothrombotic state in splenectomized patients, characterized by enhanced platelet activation. In that study, platelet and coagulation parameters improved 1 hour after blood transfusions, supporting the hypothesis that transfusion might have a protective role in platelet hemostasis. Manakeng et $\mathrm{al}^{22}$ showed that patients with thalassemia displayed increased levels of platelets and red blood cell-derived microparticles. In addition, microparticles derived from splenectomized patients induced the highest platelet activation compared with those of nonsplenectomized patients and control subjects. ${ }^{23}$

The results of the current study suggest a new mechanism of the procoagulant state in patients with thalassemia. It is shown that heparanase and TF activity are elevated in patients with thalassemia major compared with control 
subjects. The fact that no difference in these parameters has been determined between splenectomized and nonsplenectomized patients may imply that this effect is not involved in the increased risk of thrombosis in splenectomized patients. The JAK-2 inhibitor ruxolitinib seems to significantly reduce the level of heparanase in the mouse model. This is in line with a previously reported finding of a similar effect of ruxolitinib on heparanase in tumor cell lines. ${ }^{6}$ In a meta-analysis of patients with polycythemia vera treated with ruxolitinib compared with other therapies, the number of thrombotic events was lower in the ruxolitinib group, although this difference did not reach statistical significance. ${ }^{24}$ These data may suggest a decrease in heparanase levels and procoagulant activity as a possible mechanism of reduced thrombosis after exposure to ruxolitinib. Interestingly, Asperti et $\mathrm{al}^{25}$ reported that in heparanase overexpressing mice, serum and liver iron levels were elevated, whereas the hepcidin level was low. Thus, other aspects of heparanase inhibition in the context of iron homeostasis in thalassemia may emerge as beneficial.

\section{Conclusions}

The current study shows that heparanase and erythropoietin levels are elevated in patients with thalassemia major. Erythropoietin may induce heparanase up-regulation, and heparanase may contribute to the procoagulant state in these patients. In a mouse thalassemia model, inhibition of JAK-2 was found to reduce heparanase levels and could potentially reverse the prothrombotic phenotype. These results may pose heparanase inhibitors as useful therapies in this clinical setting.

\section{Acknowledgments}

We thank Prof. Israel Vlodavsky and Dr. Neta Ilan (Technion, Haifa, Israel) for providing the heparanase antibodies.

\section{Author Contributions}

H.G., S.A., and C.C. performed research and analyzed data; S.R. analyzed data; Y.N. designed research, performed research, analyzed data, and wrote the paper.

\section{References}

1. Cappellini MD, Poggiali E, Taher AT, Musallam KM: Hypercoagulability in beta-thalassemia: a status quo. Expert Rev Hematol 2012, 5: 505-512

2. Vlodavsky I, Singh P, Boyango I, Gutter-Kapon L, Elkin M, Sanderson RD, Ilan N: Heparanase: from basic research to therapeutic applications in cancer and inflammation. Drug Resist Updat 2016, 29: $54-75$
3. Nadir Y, Brenner B, Fux L, Shafat I, Attias J, Vlodavsky I: Heparanase enhances the generation of activated factor $\mathrm{X}$ in the presence of tissue factor and activated factor VII. Haematologica 2010, 95:1927-1934

4. Nadir Y, Brenner B, Zetser A, Ilan N, Shafat I, Zcharia E, Goldshmidt O, Vlodavsky I: Heparanase induces tissue factor expression in vascular endothelial and cancer cells. J Thromb Haemost 2006, 4:2443-2451

5. Nadir Y, Brenner B, Gingis-Velitski S, Levy-Adam F, Ilan N, Zcharia E, Nadir E, Vlodavsky I: Heparanase induces tissue factor pathway inhibitor expression and extracellular accumulation in endothelial and tumor cells. Thromb Haemost 2008, 99:133-141

6. Kogan I, Chap D, Hoffman R, Axelman E, Brenner B, Nadir Y: JAK-2 V617F mutation increases heparanase procoagulant activity. Thromb Haemost 2016, 115:73-80

7. Libani IV, Guy EC, Melchiori L, Schiro R, Ramos P, Breda L, Scholzen T, Chadburn A, Liu Y, Kernbach M, Baron-Lühr B, Porotto M, de Sousa M, Rachmilewitz EA, Hood JD, Cappellini MD, Giardina PJ, Grady RW, Gerdes J, Rivella S: Decreased differentiation of erythroid cells exacerbates ineffective erythropoiesis in beta-thalassemia. Blood 2008, 112:875-885

8. Yang B, Kirby S, Lewis J, Detloff PJ, Maeda N, Smithies O: A mouse model for beta 0-thalassemia. Proc Natl Acad Sci U S A 1995, 92: $11608-11612$

9. Casu C, Presti VL, Oikonomidou PR, Melchiori L, Abdulmalik O, Ramos P, Rivella S: Short-term administration of JAK2 inhibitors reduces splenomegaly in mouse models of $\beta$-thalassemia intermedia and major. Haematologica 2018, 103:e46-e49

10. Zetser A, Levy-Adam F, Kaplan V, Gingis-Velitski S, Bashenko Y, Schubert S, Flugelman MY, Vlodavsky I, Ilan N: Processing and activation of latent heparanase occurs in lysosomes. J Cell Sci 2004, 117:2249-2258

11. Shafat I, Zcharia E, Nisman B, Nadir Y, Nakhoul F, Vlodavsky I, Ilan N: An ELISA method for the detection and quantification of human heparanase. Biochem Biophys Res Commun 2006, 341:958-963

12. Nadir Y, Kenig Y, Drugan A, Shafat I, Brenner B: An assay to evaluate heparanase procoagulant activity. Thromb Res 2011, 128:e3-e8

13. Matan M, King D, Peled E, Ackerman S, Bar-Lavi Y, Brenner B, Nadir Y: Heparanase level and procoagulant activity are reduced in severe sepsis. Eur J Haematol 2018, 100:182-188

14. Huang Y, Lei Y, Liu R, Liu J, Yang G, Xiang Z, Liang Y, Lai Y: Imbalance of erythropoiesis and iron metabolism in patients with thalassemia. Int J Med Sci 2019, 16:302-310

15. Butthep P, Wisedpanichkij R, Jindadamrongwech S, Fucharoen S: Elevated erythropoietin and cytokines levels are related to impaired reticulocyte maturation in thalassemic patients. Blood Cells Mol Dis 2015, 54:170-176

16. Nevo N, Ghanem S, Crispel Y, Tatour M, Cohen H, Kogan I, BenArush M, Nadir Y: Heparanase level in the microcirculation as a possible modulator of the metastatic process. Am J Pathol 2019, 189:1654-1663

17. Nadir Y, Kenig Y, Drugan A, Zcharia E, Brenner B: Involvement of heparanase in vaginal and cesarean section deliveries. Thromb Res 2010, 126:e444-e450

18. Nadir Y, Henig I, Naroditzky I, Paz B, Vlodavsky I, Brenner B: Involvement of heparanase in early pregnancy losses. Thromb Res 2010, 125:e251-e257

19. Hardak E, Peled E, Crispel Y, Ghanem S, Attias J, Asayag K, Kogan I, Nadir Y: Heparan sulfate chains contribute to the anticoagulant milieu in malignant pleural effusion. Thorax 2020, 75:143-152

20. Huang Y, Long Y, Deng D, Liu Z, Liang H, Sun N, Xu Y, Lai Y, Cheng P: Alterations of anticoagulant proteins and soluble endothelial protein $\mathrm{C}$ receptor in thalassemia patients of Chinese origin. Thromb Res 2018, 172:61-66

21. Trinchero A, Marchetti M, Giaccherini C, Tartari CJ, Russo L, Falanga A: Platelet haemostatic properties in [beta]-thalassaemia: the effect of blood transfusion. Blood Transfus 2017, 15:413-421

22. Manakeng K, Prasertphol P, Phongpao K, Chuncharunee $S$, Tanyong D, Worawichawong S, Svasti S, Chaichompoo P: Elevated 
levels of platelet- and red cell-derived extracellular vesicles in transfusion-dependent [beta]-thalassemia/HbE patients with pulmonary arterial hypertension. Ann Hematol 2019, 98:281-288

23. Klaihmon P, Phongpao K, Kheansaard W, Noulsri E, Khuhapinant A, Fucharoen S, Morales NP, Svasti S, Pattanapanyasat K, Chaichompoo P: Microparticles from splenectomized [beta]-thalassemia/HbE patients play roles on procoagulant activities with thrombotic potential. Ann Hematol 2017, 96:189-198
24. Masciulli A, Ferrari A, Carobbio A, Ghirardi A, Barbui T: Ruxolitinib for the prevention of thrombosis in polycythemia vera: a systematic review and meta-analysis. Blood Adv 2020, 4: 380-386

25. Asperti M, Stuemler T, Poli M, Gryzik M, Lifshitz L, MeyronHoltz EG, Vlodavsky I, Arosio P: Heparanase overexpression reduces hepcidin expression, affects iron homeostasis and alters the response to inflammation. PLoS One 2016, 11:e0164183 